\title{
Role of Hydroxyl Groups in the Basic Reactivity of MgO: a Theoretical and Experimental Study
}

\author{
C. Chizallet' , G. Costentin ${ }^{1}$, H. Lauron-Pernot ${ }^{1}$, J.M. Krafft' \\ P. Bazin ${ }^{2}$, J. Saussey ${ }^{2}$, F. Delbecq ${ }^{3}$, P. Sautet ${ }^{3}$ and M. Che ${ }^{1,4}$ \\ 1 Laboratoire de Réactivité de Surface, UMR 7609 CNRS, Université Pierre et Marie Curie Paris 6, \\ 4, place Jussieu, 75252 Paris Cedex 05 - France \\ 2 Laboratoire Catalyse et Spectrochimie, UMR 6506 CNRS, ENSICAEN, Université de Caen, \\ 6, boulevard du Maréchal Juin, 14050 Caen Cedex - France \\ 3 Laboratoire de Chimie, UMR 5182 CNRS, École Normale Supérieure de Lyon, 46 Allée d'ltalie, 69364 Lyon Cedex 07 - France \\ 4 Institut Universitaire de France, 103, boulevard Saint-Michel, 75005 Paris - France \\ e-mail: chizalle@ccr.jussieu.fr - costenti@ccr.jussieu.fr - pernot@ccr.jussieu.fr - che@ccr.jussieu.fr - philippe.bazin@ensicaen.fr - \\ jacques.saussey@wanadoo.fr - francoise.delbecq@ens-lyon.fr - philippe.sautet@ens-lyon.fr
}

Résumé - Rôle des groupes hydroxyles sur la réactivité basique de MgO : étude expérimentale et théorique - Des surfaces propres (exemptes de carbonates et d'hydroxyles) et hydroxylées de $\mathrm{MgO}$ de différentes morphologies sont utilisées pour étudier la corrélation entre basicité thermodynamique de Brønsted (évaluée par le pouvoir déprotonant vis à vis du méthanol et du propyne suivi par FTIR) et réactivité basique (évaluée par le test de conversion du 2-methyl-but-3-yn-2-ol (MBOH)). Si une corrélation est obtenue dans le cas des surfaces propres, par contre pour les surfaces hydroxylées, les groupes $\mathrm{OH}$ bien que bases faibles de $\mathrm{Br} \not n s t e d$ sont plus actifs que les ions oxydes $\mathrm{O}^{2-}$. Ces groupes $\mathrm{OH}$ donnent en infra-rouge une bande étroite $v_{\mathrm{OH}}$ à haute fréquence. Afin de les identifier, des surfaces impliquant des ions $\mathrm{O}^{2-}{ }_{\mathrm{LC}}$ et $\mathrm{Mg}^{2+}{ }_{\mathrm{LC}}$ de basse coordinence (low coordination = LC) ont été modélisées par calculs DFT. Tous les sites dissocient l'eau : excepté pour les crans et bilacunes où les $\mathrm{OH}$ formés peuvent être considérés comme isolés, dans tous les autres cas, les $\mathrm{OH}$ formés sont liés par pont hydrogène. Les fréquences infra-rouge obtenues par calculs sont en accord avec le spectre expérimental qui présente deux domaines : l'un, large et situé à basse fréquence $\left(v_{\mathrm{OH}}<3700 \mathrm{~cm}^{-1}\right)$, est attribué aux hydroxyles donneurs de liaison hydrogène $\left(\mathrm{O}_{3 \mathrm{C}} \mathrm{H}, \mathrm{O}_{4 \mathrm{C}} \mathrm{H}, \mathrm{O}_{5 \mathrm{C}} \mathrm{H}\right)$, l'autre, plus étroit, à haute fréquence $\left(v_{\mathrm{OH}}>3700 \mathrm{~cm}^{-1}\right)$, correspond aux hydroxyles isolés $\left(\mathrm{O}_{2 \mathrm{C}} \mathrm{H}, \mathrm{O}_{3 \mathrm{C}} \mathrm{H}\right.$ et $\mathrm{O}_{4 \mathrm{C}} \mathrm{H}$ formés dans les crans et bilacunes) et aux hydroxyles accepteurs de liaison hydrogène $\left(\mathrm{O}_{1 \mathrm{C}} \mathrm{H}\right.$ et $\left.\mathrm{O}_{2 \mathrm{C}} \mathrm{H}\right)$. Ces derniers seraient impliqués dans la réactivité des surfaces hydroxylées vis à vis du $\mathrm{MBOH}$.

Abstract - Role of Hydroxyl Groups in the Basic Reactivity of MgO: a Theoretical and Experimental Study - Clean (i.e., carbonate- and hydroxyl-free) and hydroxylated $\mathrm{MgO}$ surfaces of various morphologies were used to study the correlation between thermodynamic Bronsted basicity (evaluated by the deprotonation of methanol and propyne followed by FTIR) and basic reactivity (evaluated by the conversion of 2-methyl-but-3-yn-2-ol (MBOH)). A correlation is evidenced for clean surfaces, but for hydroxylated surfaces, $\mathrm{OH}$ groups, though weak Brønsted bases, are much more active than oxide $O^{2-}$ ions. Some of the hydroxyl groups whose $\mathrm{v}_{\mathrm{OH}}$ infra-red stretching band is included in the narrow high-frequency $\mathrm{OH}$ 
band were shown to be responsible for such activity. In order to identify them, the irregularities of surfaces involving low coordination (LC) ions were modeled by DFT calculations (mono- and di-atomic steps for $4 C$ ions, corners, kinks and divacancies for $3 C$ ions). All of them dissociate water: except for kinks and divancancies where the $\mathrm{OH}$ formed can be considered as isolated, in all the other cases, $\mathrm{OH}$ groups are H-bonded. The $v_{O H}$ infra-red frequencies obtained by calculations are consistent with the experimental spectrum which exhibits two domains: the broad low-frequency $\left(v_{O H}<3700 \mathrm{~cm}^{-1}\right)$ domain is assigned to $\mathrm{H}$-bond donor $\mathrm{OH}$ groups $\left(\mathrm{O}_{3 \mathrm{C}} \mathrm{H}, \mathrm{O}_{4 \mathrm{C}} \mathrm{H}\right.$ and $\left.\mathrm{O}_{5 \mathrm{C}} \mathrm{H}\right)$, whereas the high-frequency narrow band $\left(\mathrm{v}_{\mathrm{OH}}>3700 \mathrm{~cm}^{-1}\right)$ corresponds to isolated $\mathrm{OH}\left(\mathrm{O}_{2 \mathrm{C}} \mathrm{H}, \mathrm{O}_{3 \mathrm{C}} \mathrm{H}\right.$ and $\mathrm{O}_{4 \mathrm{C}} \mathrm{H}$ in kinks and divacancies) and $\mathrm{H}$-bond acceptor $\mathrm{OH}$ groups $\left(\mathrm{O}_{1 \mathrm{C}} \mathrm{H}\right.$ and $\left.\mathrm{O}_{2 \mathrm{C}} \mathrm{H}\right)$. The latter are inferred to be implied in basic reactivity of hydroxylated surfaces toward $\mathrm{MBOH}$.

\section{INTRODUCTION}

Despite few industrial applications [1], heterogeneous catalysis using solid bases has lead to interesting developments in fine chemistry. However, the understanding of reactivity and selectivity obtained requires the analysis of the notion of basicity for a solid catalyst. In the literature, the Lewis basicity is evaluated by means of acidic probe molecules [2,3], such as $\mathrm{CO}_{2}$. However, the first step of a reaction (Equation 1) on a basic oxide corresponds generally to the equilibrium of deprotonation of a protic organic molecule $\mathrm{RH}$ more relevant to fine chemistry. It is thus the Brønsted basicity which is involved, the latter being defined as the ability of a species to protonate itself [4]. Taking into account the general mechanism involved for basic catalytic reactions (Equation 1), protic molecules likely to dissociate [5] appear to be very promising tools to evaluate the thermodynamic Brønsted basicity of a basic surface.

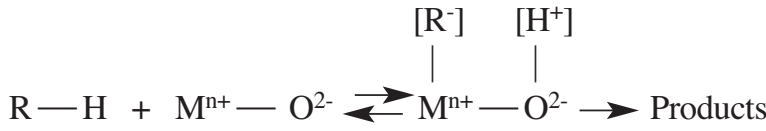

However, the first reaction step not only implies the Lewis basic site $\left(\mathrm{O}^{2-}\right.$ ion in Equation 1) to deprotonate the $\mathrm{RH}$ molecule, but also requires the participation of the cation $\mathrm{M}^{\mathrm{n}+}$ (thus of the Lewis acidity) to stabilize the generated anionic intermediate $\mathrm{R}^{-}$. Thus, it is an acid-base pair that should be considered. The further transformation of the intermediate $\mathrm{R}^{-}$ into products depends on its degree of stabilization by the surface [6]. What is the reliability of thermodynamic Brønsted data compared with the global basic reactivity which is a kinetic parameter, usually evaluated by a catalytic test reaction [7] measuring the rate of formation of products, issued from the anionic intermediate?

$\mathrm{MgO}$ is a suitable system to investigate the notion of basicity because it is a well-known basic catalyst [8] with a simple rock salt structure. If the most stable crystallographic plane is (100), there are many surface irregularities resulting in different $\mathrm{Mg}-\mathrm{O}$ pairs where $\mathrm{Mg}^{2+}$ and $\mathrm{O}^{2-}$ ions have different coordination numbers depending on their location on terraces, edges and corners with five-, four- and three-fold coordination, respectively, [9] commonly denoted as $\mathrm{Mg}^{2+} \mathrm{LC}^{2-}{ }_{\mathrm{LC}}$
( $\mathrm{LC}=$ low coordination). A schematic representation of the $\mathrm{MgO}$ surface is reported in Figure 1.

The aim of this paper is to study the correlation between thermodynamic basicity, evaluated by the adsorption of protic molecules, methanol and propyne, followed by infra-red spectroscopy, the basic reactivity of $\mathrm{MgO}$ surfaces, evaluated by the conversion of 2-methyl-but-3-yn-2-ol (MBOH) [10] and the nature of surface basic sites, modeled by DFT.

To study the influence of the coordination of ions on basicity, several $\mathrm{MgO}$ samples were synthesized so as to vary the populations of low coordinated ions. Moreover, besides $\mathrm{O}^{2-}$ sites, hydroxyl groups also act as basic sites and have been shown to promote basic reactions $[11,12]$. Indeed, it has been recently shown that surface $\mathrm{OH}$ groups of $\mathrm{MgO}$ are also involved in basic reactivity, with even higher catalytic activity than that of oxide ions [6]. Hydroxylated surfaces were prepared first by high-temperature treatment of $\mathrm{MgO}$ samples to remove carbonates and hydroxyl groups and then by rehydration to produce hydroxyl groups only. Such surfaces were studied by infra-red, and theoretical calculations so as to identify the hydroxyl groups remaining at the surface [13].

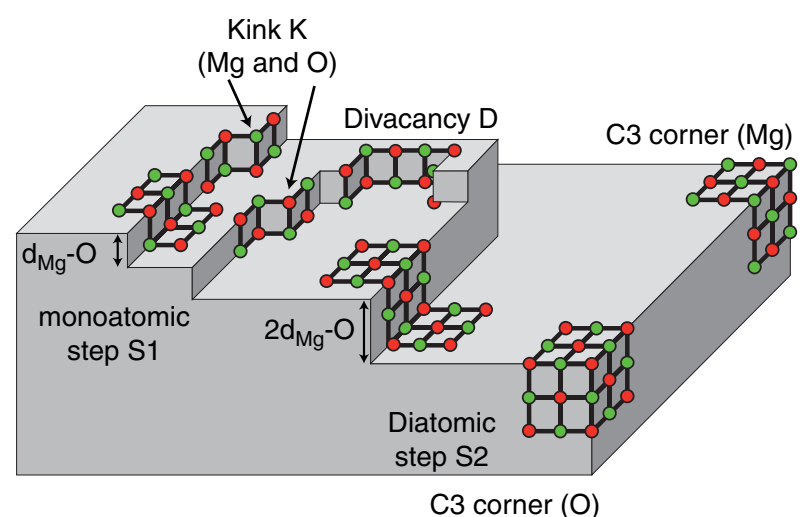

Figure 1

Schematic representation of irregularities on the $\mathrm{MgO}$ surface. The steps and corners model, proposed by Che and Tench [9] is adapted to the systems discussed. Defects modeled in the present work are shown with red $\left(\mathrm{O}^{2-}\right)$ and green $\left(\mathrm{Mg}^{2+}\right)$ spheres. 
The simulation of the $\mathrm{MgO}(100)$ surface has been extensively investigated and reported in the literature [14-20] and the conclusions are consistent with the experiments $[19,21$, 22]: both dissociative and molecular adsorptions of $\mathrm{H}_{2} \mathrm{O}$ are observed on $\mathrm{MgO}(100)$.

If flat terraces are dehydrated at room temperature, [23] stronger interactions of $\mathrm{H}_{2} \mathrm{O}$ with ions involving a lower coordination state than $5 \mathrm{C}$ are expected. However, a systematic $a b$ initio study of defects involving $4 \mathrm{C}$ and 3C ions described in a realistic way, of their interaction with water and of the geometry and thermal stability of the resulting hydroxyls, is lacking. The present work will consequently focus on the simulation of $\mathrm{MgO}$ surface irregularities and calculations of the corresponding infra-red frequencies.

\section{EXPERIMENTAL}

\subsection{Preparation of MgO Samples}

$\mathrm{MgO}$ samples were prepared as described earlier [24] by direct oxidation of metallic magnesium under oxygen flow (MgO-CVD) or by decomposition under vacuum $\left(10^{-3}\right.$ Torr; 1 Torr $=133.32 \mathrm{~Pa}$ ) of magnesium hydroxides at $1273 \mathrm{~K}$ (ramp $1 \mathrm{~K} \cdot \mathrm{min}^{-1}$ ) for $2 \mathrm{~h}$. The hydroxides were themselves prepared by precipitation of $\mathrm{Mg}\left(\mathrm{NO}_{3}\right)_{2}$, hydration of commercial $\mathrm{MgO}$ or by sol-gel routes, resulting in $\mathrm{MgO}$ samples hereafter referred to as $\mathrm{MgO}$-precipitation, $\mathrm{MgO}$-hydration and $\mathrm{MgO}$-sol-gel, respectively.

\subsection{FTIR Experiments}

Self-supported wafers of about 20 to $30 \mathrm{mg}$ were used. All spectra were registered at room temperature using a Nicolet FTIR Magna 550 spectrometer, equipped with a DTGS detector (resolution $4 \mathrm{~cm}^{-1}, 64$ scans / spectrum).

Clean $\mathrm{MgO}$ surfaces (free of carbonates and hydroxyl groups) were obtained in situ in the IR cell: wafers were first evacuated up to $673 \mathrm{~K}\left(1 \mathrm{~K} \cdot \mathrm{min}^{-1}\right)$ for $1 \mathrm{~h}$, then heated under 100 Torr of oxygen to $1023 \mathrm{~K}$ (the maximal possible temperature for the setup; $5 \mathrm{~K} \cdot \mathrm{min}^{-1}$ ), and finally evacuated at this temperature to a residual pressure of about $5.10^{-6}$ Torr. For hydroxylated surfaces, the wafers were pretreated at $1023 \mathrm{~K}$ according to the procedure used for clean surfaces. In order to obtain a partially hydroxylated and carbonate-free surface, water under an equilibrium pressure of 1 Torr was then introduced for $10 \mathrm{~min}$ at $373 \mathrm{~K}$, and finally an evacuation was performed $\left(5 \mathrm{~K} \cdot \mathrm{min}^{-1}\right)$ up to the selected temperature, which was maintained for $1 \mathrm{~h}$.

Methanol (Prolabo, RP Normapur) and propyne (Aldrich Chemical, 98\%), purified by freeze-pump-thaw, were contacted with $\mathrm{MgO}$ by successive doses at room temperature via a vacuum line connected to the spectrometer. A final
1 Torr equilibrium pressure was obtained after $15 \mathrm{~min}$ of contact with the sample. The IR spectrum of the gas phase was recorded and subtracted from that of the sample.

\subsection{DRIFT Experiments}

Diffuse reflectance FTIR (DRIFT) spectra were recorded on a Brüker IFS $66 \mathrm{~V}$ spectrometer in the $3800-600 \mathrm{~cm}^{-1}$ range (resolution $4 \mathrm{~cm}^{-1}, 256$ scans/spectrum) using a Thermo Spectra-Tech high-temperature cell allowing in situ preparation of hydroxylated samples. After a first heating to $1023 \mathrm{~K}$ $\left(5 \mathrm{~K} \cdot \mathrm{min}^{-1}\right)$ under nitrogen flow $\left(70 \mathrm{~cm}^{3} \cdot \mathrm{min}^{-1}\right)$ for $1 \mathrm{~h}$, to remove carbonate and hydroxyl groups, the sample was hydroxylated by adsorbing water vapor (about 6 Torr) diluted in nitrogen $\left(10 \mathrm{~cm}^{3} \cdot \mathrm{min}^{-1}\right)$ for $10 \mathrm{~min}$ and subsequent heating $\left(5 \mathrm{~K} \cdot \mathrm{min}^{-1}\right)$ under nitrogen $\left(70 \mathrm{~cm}^{3} \cdot \mathrm{min}^{-1}\right)$ up to the selected activation temperature, and maintained at this temperature for $15 \mathrm{~min}$. This treatment (identical to the one applied for the catalytic test) led to the so-called hydroxylated surfaces. All spectra were converted into Kubelka-Munk units after subtraction of the spectrum of a $\mathrm{KBr}$ reference sample dehydrated at $473 \mathrm{~K}$ under nitrogen $\left(70 \mathrm{~cm}^{3} \cdot \mathrm{min}^{-1}\right)$ for $2 \mathrm{~h}$.

\subsection{Methylbutynol Reaction}

Catalytic tests of methylbutynol (MBOH) conversion were performed following the procedure described earlier [6]. Clean surfaces were obtained by pretreating the catalysts (weight corresponding to $\mathrm{MgO}$ isosurface of $5 \mathrm{~m}^{2}$ ) at $1073 \mathrm{~K}$ for $2 \mathrm{~h}$ under nitrogen flow $\left(70 \mathrm{~cm}^{3} \cdot \mathrm{min}^{-1}\right)$. Hydroxylated samples were obtained following the procedure described for DRIFT experiments. The sample was then cooled to the reaction temperature, $393 \mathrm{~K}$. The reactants were oriented through the catalyst in the gas phase, the partial pressure of $\mathrm{MBOH}$ being fixed at $3.3 \mathrm{kPa}$ by bubbling nitrogen $\left(70 \mathrm{~cm}^{3} \cdot \mathrm{min}^{-1}\right)$ in liquid $\mathrm{MBOH}$ at $303 \mathrm{~K}$. Reaction products (acetone and acetylene in the case of basic reactivity) were analyzed every $120 \mathrm{~s}$ using a Varian micro-gas chromatograph equipped with a catharometric detector and a CP WAX 52 CB column.

\section{COMPUTATIONAL METHODS}

Calculations are performed in the framework of the density functional theory (DFT) and the generalized gradient approximation exchange-correlation functional of Perdew and Wang PW91 [25], as implemented in the Vienna Ab Initio Simulation Package (VASP 4.6) [26, 27]. The one electron wave function is developed on a basis set of plane waves and the interaction between core and valence electrons is described by the projector augmented wave (PAW) approach [28]. The selected description of the oxygen atomic core allows a good convergence on the energy for a cut-off of $265 \mathrm{eV}$. The convergence criterion for an electronic 
self-consistent cycle has been fixed to $10^{-6} \mathrm{eV}$ per cell. Geometry optimizations are performed within a conjugategradient algorithm until the convergence criterion on forces $\left(10^{-2} \mathrm{eV} \cdot \AA^{-1}\right)$ is reached. The slabs are not symmetrical, which induces a net dipole, and consequently a spurious electrostatic interaction between the slab and its periodic images along the $\mathrm{z}$ axis (see below). A dipolar correction along the direction perpendicular to the slab has been applied to remove this effect. This correction does not exceed $0.05 \%$ of the total cohesive energy.

In the preliminary approach exposed here, the harmonic $\mathrm{O}-\mathrm{H}$ stretching frequencies are calculated with the same energy cutoff. In the present work, moving step size of $\pm 0.005 \AA$ around the $\mathrm{O}-\mathrm{H}$ equilibrium position is used. Anharmonicity corrections are performed following the method proposed by Loffreda and co-workers [29, 30].

\section{RESULTS AND DISCUSSION}

\subsection{Thermodynamic Basicity versus Basic Reactivity}

\subsubsection{Clean Surfaces}

The characterization of samples with clean surfaces was previously reported [24]. The main results (specific surface area, crystallite size, transmission electron microscopy and photoluminescence) gathered in Table 1 enable the classification of the samples, from the least to the most irregular, from $\mathrm{MgO}-\mathrm{CVD}$ to $\mathrm{MgO}$-sol-gel.

The specific surface areas vary from 150 to $300 \mathrm{~m}^{2} \cdot \mathrm{g}^{-1}$ but there is no direct relationship with the average particle size estimated from XRD, due to various particle shapes and morphologies. Photoluminescence spectroscopy, sensitive to the coordination of oxide ions, $\mathrm{O}^{2-}$, allowed the ranking of the samples according to the relative concentration of oxide ions of lowest coordination, which increases following the sequence: $\mathrm{MgO}-\mathrm{CVD}<\mathrm{MgO}$-precipitation $\approx \mathrm{MgO}$-hydration $<\mathrm{MgO}$-sol-gel.
Methanol and propyne adsorptions both lead to dissociative and molecular adsorption modes, as shown by analysis of their respective $v_{\mathrm{CO}}$ [31] and $v_{\mathrm{C} \equiv \mathrm{C}}$ [32] broad bands and $v_{\mathrm{OH}}$ regions described in detail elsewhere [5]. It was shown that the $v_{\mathrm{CO}}$ contributions at 1100 and $1085 \mathrm{~cm}^{-1}$ and $v_{\mathrm{C} \equiv \mathrm{C}}$ contributions at 2076 and $2088 \mathrm{~cm}^{-1}$ are assigned to dissociated species. Because propyne does not have any $\mathrm{OH}$ group, the appearance of a band at $v_{\mathrm{OH}}=3441 \mathrm{~cm}^{-1}$ associated with that of $v_{\mathrm{C} \equiv \mathrm{C}}$ at 2076 and $2088 \mathrm{~cm}^{-1}$ upon propyne adsorption unambiguously evidences the deprotonation of propyne on oxide ions. In the case of methanol, the analysis of the region $v_{\mathrm{OH}}$ is more difficult due to the additional interaction of the surface with molecularly adsorbed methanol. The relative amounts of dissociated species formed by adsorption of methanol and propyne were estimated from the integrated areas of the $v_{\mathrm{CO}}$ bands at 1100 and $1085 \mathrm{~cm}^{-1}$ and of the $v_{\mathrm{OH}}$ band at $3441 \mathrm{~cm}^{-1}$, respectively. The amount of dissociated species was found to increase along the series MgO-CVD < $\mathrm{MgO}$-precipitation < MgO-hydration < $\mathrm{MgO}$-sol-gel, i.e., with increasing relative concentration of oxide ions, $\mathrm{O}^{2-}{ }_{\mathrm{LC}}$.

The basic reactivity of clean $\mathrm{MgO}$ samples was evaluated by the conversion of $\mathrm{MBOH}[6,10]$. The more the sample is enriched in oxide ions of low coordination, the higher the conversion, as reported in Table 1. Moreover, it appears from Figure 2 that the conversion of $\mathrm{MBOH}$ on clean $\mathrm{MgO}$ surfaces is clearly correlated with the deprotonation ability of the surfaces towards both methanol and propyne. Thus, in this case, thermodynamic Brønsted basicity is representative of the basic reactivity of clean $\mathrm{MgO}$ samples towards $\mathrm{MBOH}$.

\subsubsection{Hydroxylated surfaces}

Two main categories of $\mathrm{OH}$ groups are expected on $\mathrm{MgO}$ surfaces from heterolytic dissociation of water, as shown by equation (2):

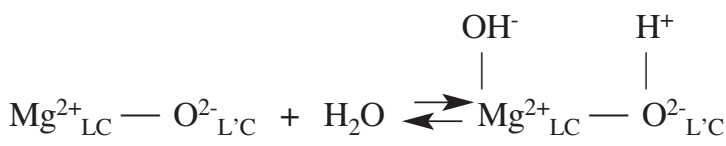

TABLE 1

Characteristics and catalytic activity of $\mathrm{MgO}$ samples.

\begin{tabular}{|c|c|c|c|c|}
\hline Sample & $\mathrm{MgO}-\mathrm{CVD}$ & $\mathrm{MgO}$-precipitation & MgO-hydration & MgO- sol-gel \\
\hline Shape of particles ${ }^{(1)}$ & cubic & irregular & irregular & irregular \\
\hline Specific surface area $\left(\mathrm{m}^{2} \cdot \mathrm{g}^{-1}\right)$ & 300 & 200 & 150 & 150 \\
\hline Particle size ${ }^{(2)}(\mathrm{nm})$ & 5 & 7.5 & 15.9 & 9 \\
\hline $\begin{array}{l}\text { Relative concentration of oxide ions } \\
\text { of low coordination }^{(3)}\end{array}$ & & & & \\
\hline Iso-surface conversion of $\mathrm{MBOH}^{(4)}$ & & & & \\
\hline \multicolumn{5}{|c|}{$\begin{array}{l}1 \text { Determined from transmission electron micrographs. } \\
2 \text { Estimated from X-Ray diffraction patterns. } \\
3 \text { Obtained from photoluminescence experiments [24]. } \\
4 \text { Pretreatment: } 1073 \mathrm{~K} \text { for } 2 \mathrm{~h}\left(\mathrm{~N}_{2}=70 \mathrm{~cm}^{3} \cdot \mathrm{min}^{-1}\right) \text {, weight corresponding to } 5 \mathrm{~m}^{2} \text {. Reaction: } \mathrm{Tr}=393 \mathrm{~K}, \mathrm{P}_{\mathrm{MBOH}}=3.3 \mathrm{kPa}, \mathrm{N}_{2} \mathrm{flow}=70 \mathrm{~cm}^{3} \cdot \mathrm{min}^{-1}[6] \text {. }\end{array}$} \\
\hline
\end{tabular}




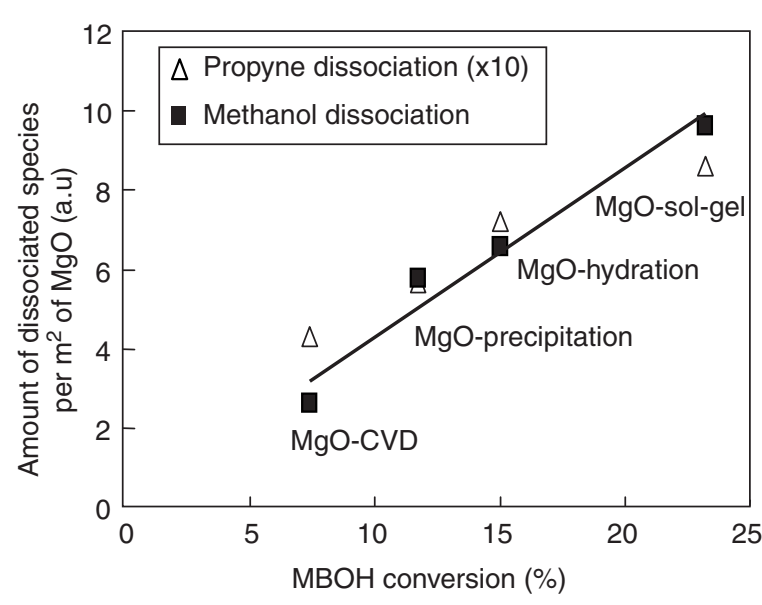

Figure 2

Correlation for clean surfaces between the thermodynamic Brønsted basicity evaluated from the integrated areas per $\mathrm{MgO} \mathrm{m}{ }^{2}$ of infra-red bands relative to dissociated methanol $\left(v_{\mathrm{CO}}=1100\right.$ and $\left.1085 \mathrm{~cm}^{-1}\right)$ and propyne $\left(v_{\mathrm{OH}}=3441 \mathrm{~cm}^{-1}\right)$ and the basic reactivity evaluated by $\mathrm{MBOH}$ conversion (the integrated areas of the $v_{\mathrm{OH}}$ band were multiplied by 10 for the sake of comparison).

- $\mathrm{OH}$ groups generated by protonation of surface oxide ions and referred to as multi-coordinated hydroxyls, i.e. bonded to several $\mathrm{Mg}^{2+}$ cations;

- $\mathrm{OH}$ groups produced by hydroxylation of surface $\mathrm{Mg}^{2+}$ cations, called mono-coordinated $\mathrm{OH}$ groups, i.e. bonded to only one $\mathrm{Mg}^{2+}$ cation.
It is expected that their acido-basic properties as well as their spectroscopic fingerprints depend on the coordination of the underlying surface ions, and on the importance of $\mathrm{H}$ bonding between $\mathrm{OH}$ groups.

Note that a hydroxylated $\mathrm{MgO}-\mathrm{CVD}$ sample was not tested in these conditions because of the surface reconstruction upon water treatment as evidenced by photoluminescence [24].

On the basis of IR-methanol experiments, it can be shown that hydroxylated surfaces further activated at $673 \mathrm{~K}$ deprotonate less methanol than clean surfaces (Fig. 3), in agreement with the results of Iizuka et al. [33] who studied the interaction of isopropanol with hydroxylated $\mathrm{CaO}$. This trend is confirmed in the case of propyne adsorption (results not shown). Thus the thermodynamic Brønsted basicity of $\mathrm{OH}$ groups seems to be lower than that of $\mathrm{O}^{2-}$ LC ions.

If the correlation observed for clean surfaces between thermodynamic basicity and basic conversion is maintained, a lower reactivity for hydroxylated surfaces is expected compared with clean surfaces. However, as evidenced by Figure 4 in the case of a hydroxylated $\mathrm{MgO}$-precipitation sample, the conversion decreases with increasing activation temperature. It can be concluded that the $\mathrm{O}^{2-}{ }_{\text {LC }}$ formed between 673 and $973 \mathrm{~K}$ upon dehydration are less active than the parent surface $\mathrm{OH}$ groups. In fact, the amount of $\mathrm{OH}$ groups measured by the areas of the DRIFT band at $3740 \mathrm{~cm}^{-1}$, also reported in Figure 4, appears to be correlated to $\mathrm{MBOH}$ conversion.

The same trends are observed for all samples, suggesting that the $\mathrm{OH}$ groups involved in the $3740 \mathrm{~cm}^{-1}$ IR band play a major role in $\mathrm{MBOH}$ conversion. This result is very important since it indicates that, in the presence of hydroxyl

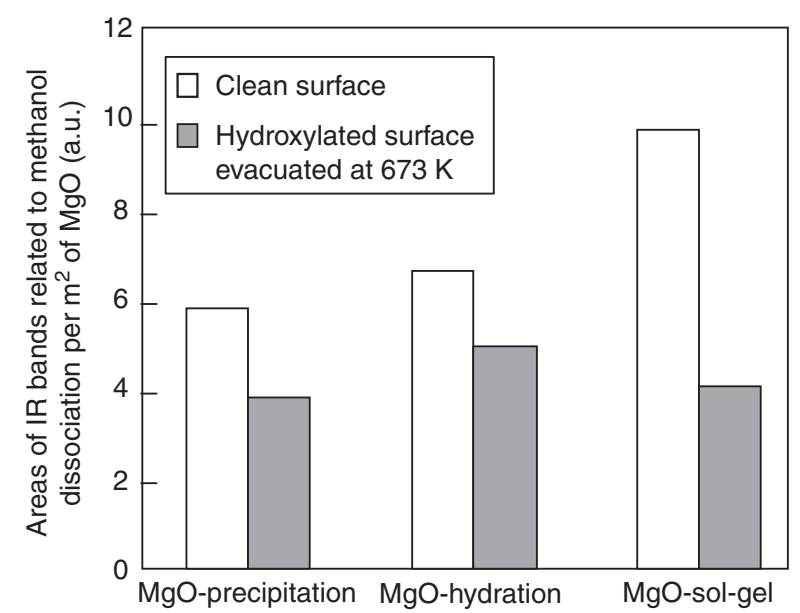

Figure 3

Areas of the $v_{\mathrm{CO}}$ bands at 1100 and $1085 \mathrm{~cm}^{-1}$ related to dissociated methanol adsorbed on clean and hydroxylated surfaces, respectively, for $\mathrm{MgO}$-precipitation, $\mathrm{MgO}$-hydration and $\mathrm{MgO}$-sol-gel samples.

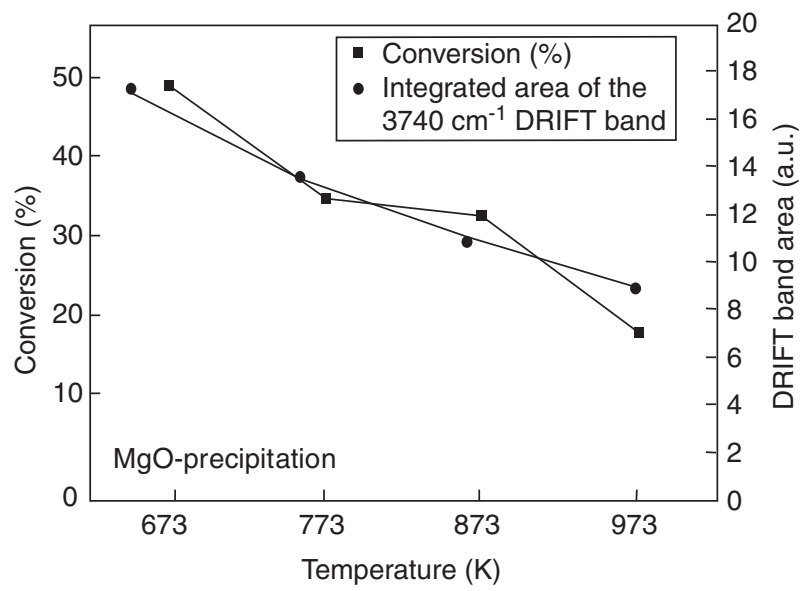

Figure 4

$\mathrm{MBOH}$ conversion and integrated area of $v_{\mathrm{OH}}$ DRIFTS band at $3740 \mathrm{~cm}^{-1}$ as a function of pretreatment temperature Tp of hydroxylated $\mathrm{MgO}$-precipitation. 
groups, there is no more correlation between thermodynamic basicity and basic reactivity. In a previous work, it was suggested that the different stability on the surface of the anionic intermediates $\mathrm{R}^{-}$(Equation 1) formed on clean and hydroxylated surfaces may explain this discrepancy [6].

As shown by Table 2, which gives the reactivity of different samples for the same pretreatment conditions, there is no link between the reactivity and the number of $\mathrm{OH}$ groups (the conversion decreases while the area goes up). Indeed, for an activation temperature of $673 \mathrm{~K}$, the $\mathrm{MgO}$-sol-gel is the least active among hydroxylated samples whereas, from measurement of the integrated area of the $3740 \mathrm{~cm}^{-1}$ band, it exhibits the highest amount of $\mathrm{OH}$ groups involved in this band.

TABLE 2

MBOH iso-surface conversion, area of FTIR band at $3740 \mathrm{~cm}^{-1}$ per $\mathrm{m}^{2}$ of hydroxylated samples activated at $673 \mathrm{~K}$ under $\mathrm{N}_{2}$.

\begin{tabular}{l|c|c|c}
\hline & MgO-precipitation & MgO-hydration & MgO-sol-gel \\
\hline $\begin{array}{l}\text { MBOH } \\
\begin{array}{l}\text { conversion } \\
\text { for } 5 \mathrm{~m}^{2}(\%)\end{array}\end{array}$ & 57.6 & 48.9 & 36.2 \\
\hline $\begin{array}{l}\text { Area of } 3740 \mathrm{~cm}^{-1} \\
\text { DRIFT band } \\
\text { per MgO m }\end{array}$ & 0.54 & 0.90 & 1.48 \\
\hline
\end{tabular}

This result suggests that only some of the $\mathrm{OH}$ groups involved in the band at $3740 \mathrm{~cm}^{-1}$ contribute to basic reactivity. Indeed, this band is rather complex and the nature of the corresponding $\mathrm{OH}$ groups is not straightforward [34-40].

\subsection{Identification of $\mathrm{OH}$ Groups Involved in Basic Reactivity by Infra-Red Spectroscopy}

\subsubsection{General Features}

Typical spectra of a hydroxylated $\mathrm{MgO}$, reported earlier by Knözinger et al. [34], are presented in Figure 5. They are decomposed into two main components: the sharp band at $3650-3800 \mathrm{~cm}^{-1}$ is usually assigned to "isolated" hydroxyl groups and a broad one at low frequency $\left(3200-3650 \mathrm{~cm}^{-1}\right)$, less thermally stable, as it almost disappears above $773 \mathrm{~K}$, is assigned to $\mathrm{H}-$ bonded $\mathrm{OH}$ groups [34-36, 38-40]. However, the shape of the former band changes for increasing evacuation temperatures, indicating that it is a multicomponent band.

Two main questions can be raised: what are the so-called "isolated" and the "H-bonded" OH groups? what is the influence of the coordination number of the surface oxygen atoms on the vibration frequency of multi-coordinated $\mathrm{OH}$ obtained by protonation of the $\mathrm{O}^{2-}{ }_{\text {LC }}$ ion?

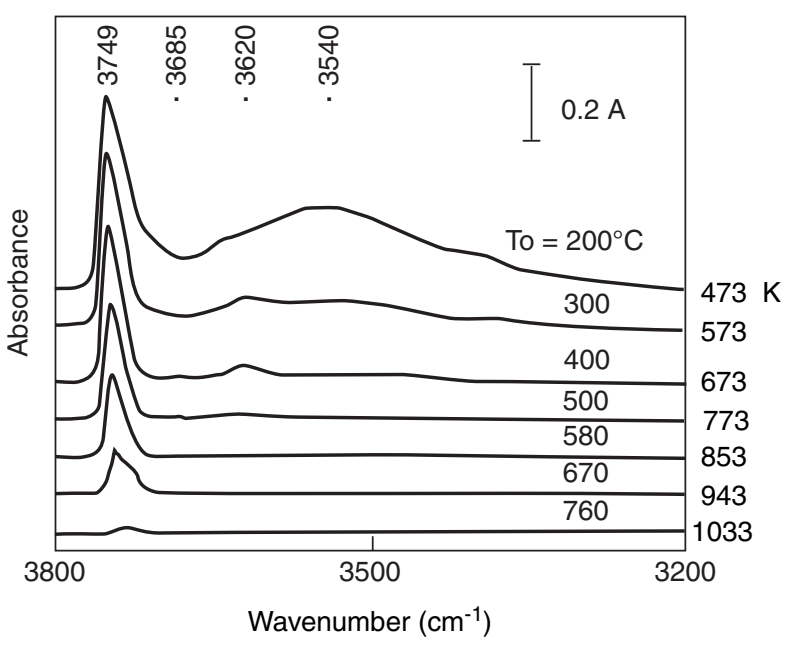

Figure 5

Spectra of hydroxylated $\mathrm{MgO}$ powdered sample exhibiting (100) planes and "high index planes" and resulting from carbonate removal by evacuation at $773 \mathrm{~K}$, followed by hydration and subsequent evacuation in the temperature range 473 $1033 \mathrm{~K}$ and at $10^{-2} \mathrm{~Pa}\left(10^{-4} \mathrm{mbar}\right)$, reproduced from [34].

\subsubsection{Study of the Construction and Hydration of Surface Irregularities by DFT Calculations}

To answer these questions, DFT calculations (VASP) were carried out to study the irregularities on $\mathrm{MgO}$ surfaces modeled by a slab approach using periodic boundary conditions. The exhaustive description of all the surface defects considered is detailed elsewhere [41].

The terminology used for each type of irregularity is given in Figure 1. 4C ions are described by mono-atomic and diatomic steps that correspond to steps of $\mathrm{d}_{\mathrm{Mg}-\mathrm{O}}$ and $2 \mathrm{~d}_{\mathrm{Mg}-\mathrm{O}}$ height, respectively: they are referred to as $\mathrm{S} 1$ and $\mathrm{S} 2$, respectively. 3C ions are modeled by $\mathrm{C} 3$ corners (length between two $3 \mathrm{C}$ ions $=3 \mathrm{~d}_{\mathrm{Mg}-\mathrm{O}}$ ), $\mathrm{D}$ divacancies (performed in the edge $\mathrm{S} 1$ by formally removing $1 \mathrm{O}$ and $1 \mathrm{Mg}$ ) and $\mathrm{K}$ kinks (obtained by formally removing 4 atoms in the edge of $\mathrm{S} 1$ ).

Dissociation of water on the corresponding relaxed systems was studied, considering different coverages by water. From the geometries obtained for the relaxed hydrated systems (some of them are reported in Fig. 6) and the negative values of hydration energies, it appears that all the defects modeled dissociate water to form hydroxyl groups whose geometry depends on the type of surface site.

In the case of $\mathrm{S} 1, \mathrm{O}_{4 \mathrm{C}}-\mathrm{H}$ are formed upon protonation of $\mathrm{O}^{2-}{ }_{4 \mathrm{C}}$ of the edge of the step, but, instead of the expected mono-coordinated $\mathrm{O}_{1 \mathrm{C}}-\mathrm{H}$ groups, the hydroxylation of $\mathrm{Mg}^{2+}{ }_{4 \mathrm{C}}$ provides di-coordinated $\mathrm{O}_{2 \mathrm{C}}-\mathrm{H}$ groups, insofar as bridging with the $\mathrm{Mg}^{2+}{ }_{5 \mathrm{C}}$ belonging to the underlying (100) plane occurs. Such bridging is no longer observed on the edge of higher step (S2) nor in the case of C3, and the 

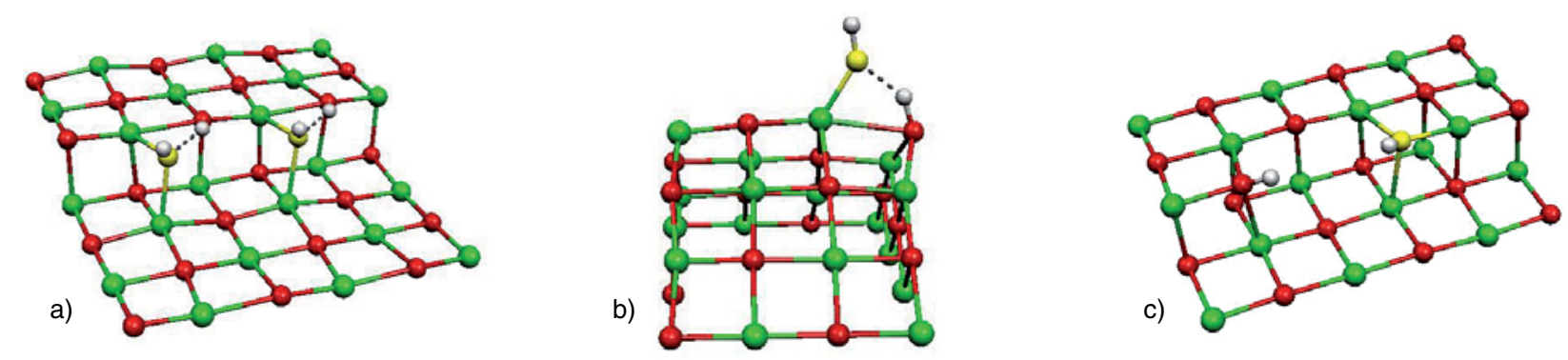

Figure 6

Perspective views of the outermost layer of hydrated systems; (a): dissociation of two water molecules on mono-atomic step S1, (b): dissociation of one water molecule on $\mathrm{C} 3\left(\mathrm{O}^{2-}{ }_{3 \mathrm{C}}\right.$ corner $)$, (c) dissociation of one water molecule on $\mathrm{Mg}^{2+}{ }_{3 \mathrm{C}}$ and $\mathrm{O}^{2-}{ }_{3 \mathrm{C}}$ ions of divacancy D. O and $\mathrm{Mg}$ atoms are depicted by red and green spheres, respectively. $\mathrm{H}$ and $\mathrm{O}$ atoms from water molecules are drawn as white and yellow spheres, respectively. H-bonding is represented as a dashed line in (a) and (b).

expected $\mathrm{O}_{1 \mathrm{C}}-\mathrm{H}, \mathrm{O}_{4} \mathrm{C}-\mathrm{H}$ and $\mathrm{O}_{3 \mathrm{C}}-\mathrm{H}$ are obtained. It is also noteworthy that in all these cases, H-bonding is observed between the two $\mathrm{OH}$ formed. Indeed, isolated $\mathrm{OH}$ groups are only observed with kinks and divacancies. Moreover, in the latter case, two equivalent $\mathrm{O}_{3 \mathrm{C}}-\mathrm{H}$ are obtained upon hydration of the divacancy due to bridging of the $\mathrm{OH}$ formed on $\mathrm{Mg}_{3 \mathrm{C}}{ }^{2+}$ with the neighboring $\mathrm{Mg}^{2+}$ cations.

Thus, the main conclusion is that, contrary to expectation from the different models of the literature [34-40]:

- mono-coordinated $\mathrm{OH}$ groups are not always formed by hydroxylation of $\mathrm{Mg}^{2+}{ }_{\mathrm{LC}}$ because whenever possible, bridging between several $\mathrm{Mg}^{2+}{ }_{\mathrm{LC}}$ provides more stable configurations leading to $\mathrm{O}_{2 \mathrm{C}}-\mathrm{H}$ (S1, for instance) and $\mathrm{O}_{3 \mathrm{C}}-\mathrm{H}$ (in D and $\mathrm{K}$ );

- isolated $\mathrm{OH}$ groups are in fact limited to very specific $\mathrm{OH}$ groups (formed on kinks and divacancies only); in all the other cases, hydrogen bonding remains between the proton and the hydroxyl issued from water dissociation.

\subsubsection{Calculation of Infra-Red Frequencies}

Infra-red harmonic frequencies were evaluated for all the relaxed hydrated systems. Anharmonic shifts were calculated for typical $\mathrm{OH}$ groups and from analysis of their structural dependence on several parameters ( $\mathrm{H}$ bonding and coordination). Corresponding shifts were applied for each series of OH groups [13].

The influence of the coordination of the oxygen of the $\mathrm{OH}$ group on the stretching frequency appears minor and difficult to rationalize. The most important parameter for a given $\mathrm{OH}$ group appears to be hydrogen bonding. As reported in Figure 7, two main domains are thus obtained.

All H-bond donor $\mathrm{OH}$ groups (scheme 1) exhibit low stretching frequencies: they are located, for example, on corners or steps.

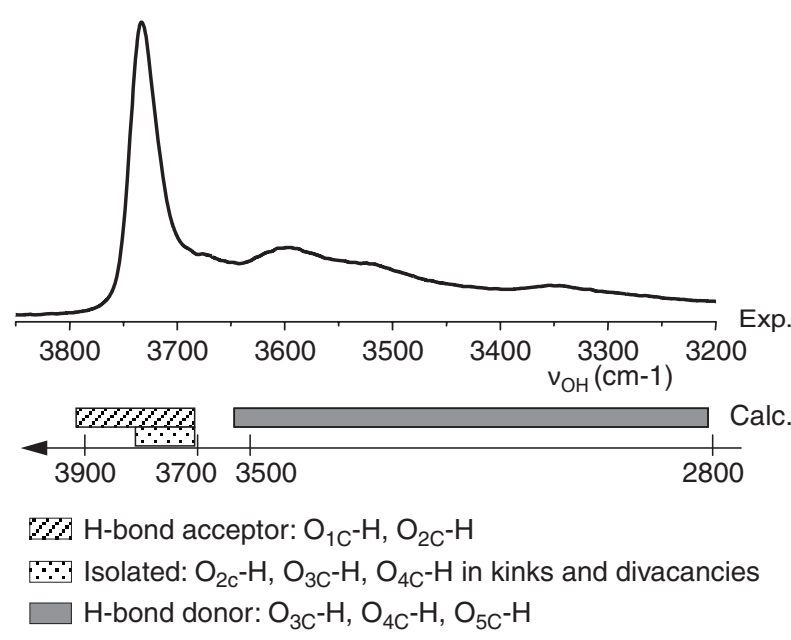

Figure 7

Experimental and calculated (for $\mathrm{P}=10^{-2} \mathrm{~Pa}$ ) infra-red spectra in the $v_{\mathrm{OH}}$ region of hydroxylated $\mathrm{MgO}$ powder.

All H-bond acceptor $\mathrm{OH}$ groups (scheme 1) exhibit significantly higher frequencies: they correspond, for example, to mono-coordinated $\mathrm{OH}$ groups in the vicinity of the corner (Fig. 6b), or di-coordinated $\mathrm{OH}$ groups obtained by bridging the expected mono-coordinated species between the edge and the underlying plane (Fig. $6 a$ ). Isolated $\mathrm{OH}$ groups also appear in this high-frequency range, and can be observed in practice in kinks and divacancies, where the expected monocoordinated species transforms into $\mathrm{O}_{3 \mathrm{C}}-\mathrm{H}$ because of multiple bridging.

$$
\text { H-bond acceptor } \stackrel{\mathrm{H}}{\mathrm{O} \ldots \ldots \ldots \ldots \ldots . . .}
$$


The frequency range of these two domains, and specially the narrow band in which very active $\mathrm{OH}$ groups in $\mathrm{MBOH}$ conversion are involved (see Sect. 3.1.2) are in quite good agreement with the experimental spectrum. Moreover, the thermal stabilities of the corresponding $\mathrm{OH}$ [41] are also consistent with the evolution of infra-red spectra versus pretreatment temperature (Fig. 5).

\subsubsection{Nature of OH Groups Involved in Basic Reactivity}

The above results also confirm, as expected from Section 3.2.1, that several types of $\mathrm{OH}$ groups (mono- and di-coordinated $\mathrm{OH}$ groups, but also $\mathrm{O}_{3 \mathrm{C}} \mathrm{H}$ and $\mathrm{O}_{4 \mathrm{C}} \mathrm{H}$ in kinks and divacancies) are involved in the experimental narrow high-frequency band.

To determine, among these $\mathrm{OH}$ groups, the ones responsible for basic reactivity of hydroxylated surfaces, it is necessary to consider the expected relative distributions of these $\mathrm{OH}$ groups on the various hydroxylated $\mathrm{MgO}$ samples. From Table 1 , the $\mathrm{MgO}$-sol-gel sample is more enriched in $\mathrm{O}_{3 \mathrm{C}}$ ions, which besides corners, involve divacancies and kinks. Note also, that both $\mathrm{OH}$ groups formed on these kinks or divacancies exhibit a stretching frequency in the high-frequency band. This is consistent with the fact that, among the hydroxylated surfaces, this sample leads to the most intense narrow band. Since, from Table 2, such an enhancement of the infra-red band is not favorable to basic reactivity, it could be inferred that $\mathrm{O}_{3 \mathrm{C}}-\mathrm{H}$ and $\mathrm{O}_{4 \mathrm{C}}-\mathrm{H}$ groups from kinks or divacancies are not responsible for basic reactivity. By contrast, mono- and di-coordinated $\mathrm{OH}$ groups can explain the high reactivity of hydroxylated samples.

\section{CONCLUSION}

The goal of this work was to correlate the Brønsted basicity and the basic reactivity of $\mathrm{MgO}$ surfaces evaluated by adsorption of protic molecules (methanol and propyne) followed by FTIR and MBOH conversion, respectively. The nature of the $\mathrm{MgO}$ samples was varied by synthesis and pretreatment, leading to surfaces involving different distributions of sites of low coordination and coverages by hydroxyl groups.

In the case of clean $\mathrm{MgO}$ samples, the higher the concentration of basic oxide ions of low coordination, $\mathrm{O}^{2-}{ }_{\mathrm{LC}}$, the higher the deprotonation ability toward methanol and propyne and the higher the MBOH conversion. Such correlation between thermodynamic basicity and basic reactivity observed for clean surfaces is no longer observed for hydroxylated surfaces, probably because of different stabilization of the anionic intermediates formed on the surfaces.

The correlation between the area of the DRIFT $v_{\mathrm{OH}}$ band at $3740 \mathrm{~cm}^{-1}$ of samples pretreated in situ at increasing activation temperature with the $\mathrm{MBOH}$ conversion level suggests that hydroxyl groups characterized by the band at
$3740 \mathrm{~cm}^{-1}$ act as active basic sites. However, by comparing the different samples, it is deduced that only part of $\mathrm{OH}$ groups present in the multicomponent infra-red band are concerned.

To identify the nature of $\mathrm{OH}$ groups implied in $\mathrm{MBOH}$ conversion, DFT calculations were performed. Different kinds of surface irregularities implying $4 \mathrm{C}$ and $3 \mathrm{C} \mathrm{Mg}^{2+}$ and $\mathrm{O}^{2-}$ ions were modeled. From their interaction with water (different $\mathrm{OH}$ coverages were studied), all the irregularities modeled are found to be able to dissociate water. Except for kinks and divacancies where the $\mathrm{OH}$ formed can be considered as isolated, in all the other cases, they are H-bonded. Moreover, contrary to the formation of two different $\mathrm{OH}$ groups (a mono-coordinated $\mathrm{O}_{1 \mathrm{C}} \mathrm{H}$ on $\mathrm{Mg}^{2+}$ and a multicoordinated $\mathrm{O}_{\mathrm{LC}} \mathrm{H}$ resulting from the protonation of $\mathrm{O}^{2-}{ }_{\mathrm{LC}}$ ), expected for water dissociation, it is found that, in some peculiar systems such as the mono-atomic step, kink or divacancy, mono-coordinated $\mathrm{O}_{1 \mathrm{C}} \mathrm{H}$ become finally more stable by bridging with neighboring $\mathrm{Mg}^{2+}$ cations, resulting in dicordinated $\mathrm{O}_{2 \mathrm{C}} \mathrm{H}$ (on mono-atomic steps) or in three-coordinated $\mathrm{O}_{3 \mathrm{C}} \mathrm{H}$ on kinks and divacancies. Thus, in this particular case, the two $\mathrm{O}_{3 \mathrm{C}} \mathrm{H}$ generated by dissociation are equivalent.

Calculations of the related infra-red $v_{\mathrm{OH}}$ harmonic frequencies corrected by anharmonic shift lead to two domains that are quite consistent with the experimental spectrum. A broad domain at low frequency $v_{\mathrm{OH}}<3700 \mathrm{~cm}^{-1}$ includes the H-bond donor $\mathrm{OH}$ groups and a narrow one at high frequency $v_{\mathrm{OH}}>3700 \mathrm{~cm}^{-1}$ corresponds to $\mathrm{H}$-bond acceptor $\mathrm{OH}$ groups and isolated $\mathrm{OH}\left(\mathrm{O}_{2} \mathrm{H}, \mathrm{O}_{3 \mathrm{C}} \mathrm{H}\right.$ and $\mathrm{O}_{4 \mathrm{C}} \mathrm{H}$ in kinks).

Further work to improve the results obtained by the use of a higher cutoff and calculations with cluster models are in progress. From the present results, it is inferred, on the basis of the analysis of the topologies of several surfaces versus basic reactivity, that only mono- and di-coordinated $\mathrm{OH}$ groups are responsible for basic reactivity. Complementary to this infra-red approach that allowed the identification of the active $\mathrm{OH}$ groups, a similar combined experimental and theoretical approach based on ${ }^{1} \mathrm{H}$ MAS NMR could be very promising to quantify precisely the amount of each type of $\mathrm{OH}$ group on $\mathrm{MgO}$.

\section{ACKNOWLEDGMENTS}

The authors wish to express their sincere gratitude to Pr. E. Knözinger of the University of Wien for kindly providing the $\mathrm{MgO}-\mathrm{CVD}$ sample. They also thank Dr D. Loffreda from ENS-Lyon for very fruitful discussions.

\section{REFERENCES}

1 Tanabe, K. and Hoelderich, W.F. (1999) Industrial applications of solid acid-base catalysts. Appl. Catal. A-Gen., 181, 399. 
2 Lavalley, J.C. (1996) Infra-red spectroscopic studies of the surface basicity of metal oxides and zeolites using adsorbed probe molecules. Catal. Today, 27, 377.

3 Aramendia, M.A., Borau, V., Jimenez, C., Marinas, A., Marinas, J.M. and Urbano, F. (2002) Isomerization of 3phenyl-1-propene (alkylbenzene) over base catalysts. $J$. Catal., 211, 556.

4 Brønsted, J.N. (1923) Einige Bemerkungen über den Begriff der Säuren und Basen. Recl. Trav. Chim. Pay.-B., 42, 718.

5 Chizallet, C., Bailly, M.L., Costentin, G., Lauron-Pernot, H., Krafft, J.M., Bazin, P., Saussey, J. and Che, M. (2006) Thermodynamic Brønsted basicity of clean $\mathrm{MgO}$ surfaces determined by their deprotonation ability: role of $\mathrm{Mg}^{2+}-\mathrm{O}^{2-}$ pairs. Catal. Today, in press.

6 Bailly, M.L., Chizallet, C., Costentin, G., Krafft, J.M., Lauron-Pernot, H. and Che, M. (2005) A spectroscopy and catalysis study of the nature of active sites of $\mathrm{MgO}$ catalysts: Thermodynamic Brønsted basicity versus reactivity of basic sites. J. Catal., 235, 413.

7 Handa, H., Fu, Y., Baba, T. and Ono, Y. (1999) Characterization of strong solid bases by test reactions. Catal. Lett., 59, 195.

8 Hattori, H. (2001) Solid base catalysts: generation of basic sites and application to organic synthesis. Appl. Catal. A-Gen., 222, 247.

9 Che, M. and Tench, A.J. (1980) Characterization and reactivity of mononuclear oxygen species on oxide surfaces. AERE Report - R 9971. Adv. Catal., 31 (1982), 77.

10 Lauron-Pernot, H., Luck, F. and Popa, J.M. (1991) Methylbutynol: a new and simple diagnostic tool for acidic and basic sites of solids. Appl. Catal. A-Gen., 78, 213.

11 Zhang, G., Hattori, H. and Tanabe, K. (1988) Aldol addition of acetone, catalyzed by solid base catalysts: magnesium oxide, calcium oxide, strontium oxide, barium oxide, lanthanum(III) oxide and zirconium oxide. Appl. Catal., 36, 189.

12 Hoq, M.F., Nieves, I. and Klabunde, K.J. (1990) Mechanistic studies of hydrocarbon $\mathrm{CH} /$ deuterium exchange over thermally activated magnesium oxide. J. Catal., 123, 349.

13 Chizallet, C., Costentin, G., Che, M., Delbecq, F. and Sautet, P. (2006) Infra-red characterization of hydroxyl groups on MgO: a periodic DFT study (in preparation).

14 Giordano, L., Goniakowski, J. and Suzanne, J. (1998) Partial dissociation of water molecules in the $(3 \times 2)$ water monolayer deposited on the $\mathrm{MgO}(100)$ surface. Phys. Rev. Lett., 81, 1271 .

15 Odelius, M. (1999) Mixed molecular and dissociative water adsorption on $\mathrm{MgO}(100)$. Phys. Rev. Lett., 82, 3919.

16 Finocchi, F. and Goniakowski, J. (2001) Interaction of a water molecule with the oxygen vacancy on the $\mathrm{MgO}(100)$ surface. Phys. Rev. B, 64, 125426 .

17 Sitte, L.D., Alavi, A. and Lynden-Bell, R.M. (2000) The structure and spectroscopy of monolayers of water on $\mathrm{MgO}$. An ab initio study. J. Chem. Phys., 113, 3344.

18 Lynden-Bell, R.M., Sitte, L.D. and Alavi, A. (2002) Structures of adsorbed water layers on $\mathrm{MgO}$. An ab initio study. Surf. Sci., 496, L1.

19 Kim, Y.D., Lynden-Bell, R.M., Alavi, A., Stultz, J. and Goodman, D.W. (2002) Evidence for partial dissociation of water on flat $\mathrm{MgO}(100)$ surfaces. Chem. Phys. Lett., 352, 318.
20 Giordano, L., Goniakowski, J. and Suzanne, J. (2000) Reversibility of water dissociation on the $\mathrm{MgO}(100)$ surface. Phys.Rev. B, 62, 15406.

21 Kim, Y.D., Stultz, J. and Goodman, D.W. (2002) Dissociation of water on $\mathrm{MgO}(100)$. J. Phys. Chem. B, 106, 1515 .

22 Yu, Y., Guo, Q., Wang, E. and Möller, P.J. (2003) Partial dissociation on a $\mathrm{MgO}(100)$ thin film. Phys. Rev. B, 68, 115414.

23 Stimiman, M.J., Huang, C., Scott Smith, R., Joyce, S.A. and Kay, B.D. (1996) The adsorption and desorption of water on single crystal $\mathrm{MgO}(100)$ : the role of surface defects. J. Chem. Phys., 105, 1295.

24 Bailly, M.L., Costentin, G., Lauron-Pernot, H., Krafft, J.M. and Che, M. (2005) Physicochemical and in situ photoluminescence study of the reversible transformation of oxide ions of low coordination into hydroxyl groups upon interaction of water and methanol with MgO. J. Phys. Chem. B, 109, 2404.

25 Perdew, J. and Wang, Y. (1992) Pair-distribution function and its coupling-constant average for the spin-polarized electron gas. Phys. Rev. B, 45, 13244.

26 Kresse, G. and Hafner, J. (1994) Ab initio molecular-dynamics simulation of the liquid-metal-amorphous-semiconductor transition in germanium. Phys. Rev. B, 49, 14251.

27 Kresse, G. and Furthmüller, J. (1996) Efficiency of ab-initio total energy calculations for metals and semiconductors using a plane-wave basis set. Comput. Mat. Sci., 6, 15 .

28 Kresse, G. and Joubert, D. (1999) From ultrasoft pseudopotentials to the projector augmented-wave method. Phys. Rev. $B, \mathbf{5 9}, 1758$

29 Loffreda, D. (1999) Modélisation théorique de l'adsorption et de la réactivité de la molécule NO sur les surfaces de catalyseurs à base de palladium, de rhodium et d'alliage palladiummanganèse. Thesis, Université Claude Bernard-Lyon I.

30 Loffreda, D., Simon, D. and Sautet, P. (1998) Vibrational frequency and chemisorption site: a DFT-periodic study of NO on $\mathrm{Pd}(111)$ and $\mathrm{Rh}(111)$ surfaces. Chem. Phys. Lett., 291, 15.

31 Bensitel, M., Saur, O. and Lavalley, J.C. (1991) Use of methanol as a probe to study the adsorption sites of different MgO samples. Mater. Chem. Phys., 28, 309.

32 Huber, S. and Knözinger, H. (1999) Adsorption of CH-acids on magnesia. A FTIR-spectroscopic study. J. Mol. Catal. AChem., 141, 117.

33 Iizuka, T., Hattori, H., Ohno, Y., Sohma, J. and Tanabe, K. (1971) Basic sites and reducing sites of calcium oxide and their catalytic activities. J. Catal., 22, 130.

34 Knözinger, E., Jacob, K.H., Singh, S. and Hofmann, P. (1993) Hydroxyl groups as IR active surface probes on $\mathrm{MgO}$ crystallites. Surf. Sci., 290, 388.

35 Anderson, P.J., Horlock, R.F. and Olivier, J.F. (1965) Interaction of water with the magnesium oxide surface. $T$. Faraday Soc., 61, 2754.

36 Tsyganenko, A.A. and Filimonov, V.N. (1973) Infra-red spectra of surface hydroxyl groups and crystalline structure of oxides. J. Mol. Struct., 19, 579.

37 Shido, T., Asakura, K. and Iwasawa, Y. (1989) The hydrogen exchange reaction of surface deuteroxyl groups on $\mathrm{MgO}$ with $\mathrm{H}_{2}$. J. Chem. Soc. Faraday T., 85, 441 .

38 Coluccia, S., Marchese, L., Lavagnino, S. and Anpo, M. (1987) Hydroxyls on the surface of $\mathrm{MgO}$ powders. Spectrochim. Acta A, 43, 1573. 
39 Coluccia, S., Lavagnino, S. and Marchese, L. (1988) The hydroxylated surface of magnesium oxide powders and the formation of surface sites. Mat. Chem. Phys., 18, 445 .

40 Morrow, B.A. (1990) Surface groups on oxides. Stud. Surf. Sci.Catal., 57, 161.
41 Chizallet, C., Costentin, G., Che, M., Delbecq, F. and Sautet, P. (2006) Revisiting acido-basicity of $\mathrm{MgO}$ surface by periodic DFT calculations: role of surface topology and ion coordination on water dissociation (submitted).

Final manuscript received in June 2006 work owned by others than IFP must be honored. Abstracting with credit is permitted. To copy otherwise, to republish, to post on servers, or to redistribute to lists, requires prior specific permission and/or a fee: Request permission from Documentation, Institut français du pétrole, fax. +33147527078 , or revueogst@ifp.fr. 